\title{
Enhancing primary school pupils' mathematics creative ability through activity based learning approach
}

\author{
Bright Lhechukwu NWOKE \\ Department of Mathematics, Alvan Ikoku Federal College of Education, Imo State, Nigeria \\ *Corresponding author: bincng@yahoo.com | Phone Number: 08033404186
}

\section{ARTICLE INFO}

Received: 22-03-2020

Received in revised: 24-05-2021

Accepted: 18-09-2021

Available online: 30-10-2021

\section{KEYWORDS}

Activity based learning;

Creative ability;

Achievement;

Mathematics

\begin{abstract}
A B S T R A C T
Mathematics creativity is very important in studying mathematics at every level of education but less attention is paid to it in the teaching-learning process and this has resulted to poor performance in the subject. The study investigated how activity based learning approach can enhance the creative skills of primary school pupils. A sample of 185 pupils from six purposively selected government owned primary schools in Owerri west local Government area of Imo state was used for the study. The study was a quasi-experimental research type adopting the pre-test, posttest non equivalent control design. The instrument for data collection was a researcher made objective test titled "Mathematics Creativity Test (GAT)"Instrument which had reliability coefficient of 0.79 determined using Kuder-Richardson formula $\left(\mathrm{KR}_{21}\right)$. The experiment group was taught geometric concepts using Activity-Based Learning Approach while the control group was taught using the traditional approach. The data generated was analyzed using mean and standard deviation to answer research questions while the hypotheses were tested using ANCOVA statistical tool at 0.05 level of significance. The result of the study revealed that Activity-Based Learning Approach enhanced pupils' mathematics creative ability irrespective of gender and ability levels. Based on the result, it was recommended that Mathematics teachers at the primary school level should apply pupils centered approaches such as activity-based learning approach in teaching to enhance pupils' creativity in mathematics.
\end{abstract}

\section{INTRODUCTION}

Mathematics is a very important subject at the primary school level as it prepares the pupils for future education and meaningful living in the society. According to Celik (2018) the importance of mathematics to man has accounted for its inclusion in school curriculum as a compulsory subject for every child of school age to acquire the appropriate mathematical skills that will enable him cope with life challenges. With regards to this, mathematics should be taught as a core subject to all students at primary and secondary school levels in order to give a sound basis for scientific and reflective thinking, and prepare them for the next level of education. This situation has not been realistic as a result of primary school mathematics teachers' consistent use of the unproductive traditional method of teaching. This method of teaching allows the teacher to take total control of the learning process making the pupils to be very passive and less creative in the classr- oom. Azuka (2013) supporting this noted that, as at now many teachers in Nigerian schools still use the traditional or lecture method in which teachers talk and students listen and copy notes. The situation is worst at the primary school level where a teacher is made to teach all the subjects in a class irrespective of his area of subject specialization. This method of teaching will continue to promote the abstract nature of mathematics and subsequent students' poor achievement. According to Nwoke, Nwoga and Emenyeonu (2018) Mathematics is associated with problem solving situations and the success of students in this subject is determined by their problem solving abilities. Teaching of mathematics should be such that, creative abilities of the students are given maximum consideration. Every mathematics teaching and learning must be directed to formation of the students' mindset in the direction of creative problem solving abilities through 
practical or activity based learning. NCTM (2000) stated that students need to be provided with challenging problems that can stimulate students to develop diverse and sound ways of mathematical thinking and to think creatively, while NCF (2005) suggested that creativity in arts, literature and other domains of knowledge is closely linked and education must provide means and opportunities to enhance child's creative expression.

Creativity is seen as the development of imaginative thought that gives way to new ideas and innovations leading to solution to problems. Runco cited in Ayele (2016) describes creativity as a multifaceted construct involving both "divergent and convergent thinking, problem finding and problem solving, self-expression, intrinsic motivation, a questioning attitude, and selfconfidence".Mkpae andObowu-Adutcha (2017) noted that creativity consists of the capacity of an individual to create or produce an entirely new or novel idea or programme or by the arrangement or re-planning or reshaping of what is already known to take a novel position. Creativity is innate as well as acquired which can be invigorated to process and get the product. Sriraman (2004) believes that creativity is not only associated to just the original work of mathematicians but also discovering something not already known by one, even if the result is hitherto known to others. Vale, Pimentel, Cabrita, Barbosa, and Fonseca, (2012) stated that creativity involves divergent thinking contributing to higher order reasoning, which highlights three main dimensions: fluency, flexibility and originality (novelty). Fluency is the ability to generate a large number of different solutions obtained by the student for the same task. The flexibility is the ability to produce a variety of different ideas about the same problem, organized in various categories. Originality is the ability to create ideas that have been identified as unique as compared to students in the same group.

Mathematical creativity deals with the development of new ideas and multiple solutions of solving mathematical problems. Noraini and Norjoharuddeen in Nwoke et al (2017) described mathematics creativity as an ability to analyze a given problem in many ways, observe patterns, see likenesses and differences, produce multiple ideas and decide upon a suitable method to tackle unfamiliar mathematics situation. Students must be exposed to mathematics learning which leads to unfamiliar mathematical situations that will drive their creative thinking. Sriraman (2004) proposed that at the professional level mathematical creativity can be defined as:

1. The ability to produce original work that significantly extends the body of knowledge (which could also include significant syntheses and extensions of known ideas)
2. The ability to open up avenues of new questions for other mathematicians and at the school levels as:

3. The process that results in unusual (novel) and/or insightful solution(s) to a given problem or analogous problems, and/or,

4. The formulation of new questions and/or possibilities that allow an old problem to be regarded from a new angle.

Mathematics creativity enables students to be involved in designing, planning, constructing, executing and inventing new ideas. The development of mathematical creativity among pupils is dependent on the teachers' classroom practices. Mehdi, Narges and Shahrnaz (2012) indicated that teachers, whose approaches are based on guiding students to think creatively and flexibly about mathematical ideas, establish classroom environments in which students have shared their insights and ideas. In such environments, teachers do not tell students the solution, instead, through offering some necessary hints which are of great help to students help them to engage in challenging problem solving situations and reflect on their own ideas in order to gain a new insight into the problem. According to Vale and Barbosa (2015) learning environments, where tasks give students opportunities to use several strategies to solve and formulate their own problems, may involve them in rich mathematical explorations, increase their motivation and encourage them to investigate, make decisions, generalize, look for patterns and connections, communicate, discuss ideas and identify alternative paths. The application of students centered approach such as activity based learning has the ability to foster creativity among primary school pupils since it allows them to control their learning.

Activity based learning is a range of pedagogical approaches to teaching. Its main concern is based upon the fact that learning should be based on doing some hands-on, minds-on or hearts-on experiments and activities. The idea of activity based learning strategy is said to be rooted in the common notion that children are active learners rather than passive recipients of information (Celik, 2018). Okwudishu (2011) defined active learning as a method where the teacher only acts as a facilitator and learners are at the centre of the learning process by their high involvement in practical activities and discussion. It is the mode of learning guided by the assumption that (i) significant learning takes place when the subject matter is perceived by the learner as relevant to their own purpose. (ii) Much significant learning is acquired through doing (iii) Learning is facilitated by the learner's responsible participation in the learning process. Malhotra, Singh, Pandey, Nayyar, Sharma and Singh (2015) noted that activity based learning gives them an opportunity to explore their own self. It provides students with a similar set of experiences so everyone can participate in discussion 
on a level of playing field, despite their socio-economic status. It compels student thinking by requiring understanding of the observed events, rather than memorizing the correct responses. It encourages questioning of the observed events and the resulting data. It promotes cause and effect thinking and diminishes dependence upon authority. Activity based learning is noted to give room to cooperative interaction which triggers creativity. Ayele (2016) stated that mathematical creativity can be fostered with the help of problem posing and problem solving activities in a cooperative learning environment with proper feedback.

\section{Statement of the Problem}

Teaching and learning of mathematics in primary schools today has neglected the development of mathematical creativity among the pupils and this has gone a long way to demean their problem solving abilities which in turn result to poor achievement in the subject. It is important that mathematics is taught in such a way that pupils will develop some skills such as creative ones based on mathematical knowledge and understanding of the subject which will allow them to build, adapt, and solve mathematical problems in the classroom.

Teachers must apply strategies that foster environments that motivate their pupils to learn and develop creative abilities and not strategies that reduce learning to memorization and render pupils passive in the classroom. Vale and Barbosa (2015) stated that environments where students have the opportunity to solve mathematical problems, using diverse strategies, and formulate their own problems, allows them to be engaged in their exploration, increasing motivation and encouraging them to investigate, to make decisions, to look for patterns and connections, to generalize, to communicate, to discuss ideas and identify alternatives.

The study was therefore carried out to investigate how activity based learning approach will enhance primary school pupils mathematical creativity which will reflect in their achievements.

\section{Purposes of the study}

The main purpose of the study was to investigate activity based learning with respect to enhancement of primary school pupils' creativity in mathematics. Specifically, the study will determine weather:

1. Primary school pupils' taught mathematics using activity based learning approach will have better mathematics creative ability than those taught using traditional learning approach.

2. High and low ability pupils taught mathematics using activity based learning approach will differ in their mathematics creative scores.
3. Enhancement of mathematics creative ability of primary school pupils using activity based learning approach is dependent on gender.

\section{Research Questions}

The following study questions guided the study:

1. What is the difference between the mathematics creative ability mean scores of pupils' taught mathematics using activity based learning approach and those taught using traditional approach?

2. What is the difference between the mathematics creative ability mean scores of high and low ability pupils taught mathematics using activity based learning approach?

3. What is the difference between the mathematics creative ability mean scores of male and female pupils taught mathematics using activity based learning approached?

\section{Hypotheses}

The following hypotheses were formulated to guide the study:

Ho1: There is no significant difference between the mathematics creative mean scores of pupils taught mathematics using activity based learning approach and those taught using traditional approach.

Ho2: There is no significant difference between the mathematics creative mean scores of high and low ability pupils taught mathematics using activity based learning approach.

$\mathrm{Ho}_{3}$ : There is no significant difference between mathematics creative mean scores of male and female pupils taught mathematics using activity based learning approach.

\section{METHODS}

The study was a quasi-experimental type adopting the pretest posttest non equivalent control design. This design was adopted since it was not possible to carryout randomization on the sample of the study. The population of the study consists of all primary six pupils in government primary schools in Owerri west local Government area of Imo State. The sample of the study consists of one hundred and eighty-five (185) primary six pupils selected purposively from four primary schools, the sample further consists of 85 male and 100 female pupils. The control group had one hundred and (102) pupils while the experiment group had seventy eight (78) pupils with thirty five (35) males and forty three (43) females. Also the experiment group had twenty five (25) high ability pupils and fifty three (53) low ability pupils who were identified through their existing information. 
The instrument for data collection was a "Mathematics creativity Test (MAT)" instrument constructed by the researcher based on table of specification. The instrument was divided into 3 parts, part A consists of 15 objective questions scored over 30mrks with options ranging from A-D with one correct option, part B consist of 4 practical questions scored over $40 \mathrm{mrks}$ and part $\mathrm{C}$ consist of 3 theoretical questions scored over $30 \mathrm{mrks}$. The instrument was validated by 2 Mathematics Educationist and a measurement and evaluation expert, their inputs guided the restructuring of the instrument. The reliability of the instrument was determined by administering it to 20 primary six pupils outside the study sample but with same characteristics. Their responses were analyzed using Kuder-Richardson formula $\left(\mathrm{KR}_{21}\right)$ which gave a reliability coefficient of 0.79 which was acceptable for the study. In each of the four schools selected, two classes were randomly assigned to control and experiment groups. The experiment and control groups were pre-tested to determine their cognitive base before the study. The experiment group was taught geometry using activity based learning approach by a trained research assistant.

The research assistant was trained on the application of the approach three times in a week for two weeks using one hour in each contact. This involved use of papers, cardboard sheets and plane sheets to demonstrate and construct angles and their properties. The experiment group was taught types of angles and their properties through activity based learning approach which allowed the teacher to guide the pupils through creating different forms of triangular shapes, identifying their properties, and their enclosed angles. The pupils were allowed to discover the sum of angles in different forms of triangles through cutting edges of papers and joining such to form a straight line showing 180 degrees, and others such as 90 degrees, 360 degrees etc. The approach allowed the pupils to cooperate with each other, share ideas, interact with the teacher, ask questions and have answers where necessary. The researcher monitored the entire process to ensure that the procedure went as outlined in the lesson plan. The control group was taught the same concept by their regular mathematics teacher using the traditional approach as outlined in the lesson plan. The teacher controlled the entire learning process as the pupils were at the receiving end without contributions. The entire process lasted for three weeks and a posttest was administered to them using a rearranged version of the pretest instrument and marked over 100percent. The data generated were analyzed using mean and standard deviation to answer research questions while the hypotheses were tested using ANCOVA statistical tool at 0.05 level of significance.

\section{RESULTS AND DISCUSSION}

Research question 1:

What is the difference between the mathematics creative ability mean scores of pupils' taught mathematics using activity based learning approach and those taught using traditional approached?

Table 1 showed that the experimental group had a mean score of 31.56 and standard deviation of 8.22 in the pretest and mean score of 49.74 and a standard deviation of 8.64 in the posttest which gave a difference in the mean score of 18.18. The control group had a mean score of 32.42 and a standard deviation of 8.87 in the pretest and a mean score of 33.85 and a standard deviation of 11.50 in the posttest which gave a difference in the mean score of 1.43 . These gave a difference in the mean score of 16.74 in favour of the experiment group.

\section{Research question 2:}

What the difference between the mathematics creative mean scores of high and low ability pupils taught mathematics using activity based learning approached?.

Table 2 showed that the high achievers had mean score of 32.69 and standard deviation of 8.68 in the pretest and mean score of 46.11 and standard deviation of 12.26 in the posttest which gave a difference in mean of 13.42 . The low achievers had mean score of 31.28 and standard deviation of 8.45 in the pretest and mean score of 36.14 and standard deviation of 11.84 in the posttest which gave a difference in mean of 4.86. These gave a difference in mean score of 8.52 in favour of the high ability pupils.

\section{Research question 3:}

What is the difference between the mathematics creative ability mean scores of male and female pupils taught mathematics using activity based learning approached?.

Table 3 showed that male pupils had mean score of 31.75 and standard deviation of 8.85 in the pretest and mean score of 51.26 and standard deviation of 8.44 in the posttest which gave a difference in mean of 19.51. The female pupils had mean score of 32.28 and standard deviation of 8.40 in the pretest and mean score of 48.51 and standard deviation of 8.72 in the posttest which gave a difference in mean of 16.43 . These gave a difference in mean score of 3.04 in favour of the males.

Table 4 showed that, p-value of .330 for ability is greater than $\alpha$-value of 0.05 , based on the result, the null hypothesis is upheld at 0.05 level of significance. Table 4 showed that the p-value of .678 for gender is greater than $\alpha$-value of 0.05 , based on the result, the null hypothesis is upheld at 0.05 level of significance. 
Ho1: There is no significant difference between the mathematics creative mean scores of pupils taught mathematics using activity based learning approach and those taught using traditional approached.

Ho2: There is no significant difference between the mathematics creative mean scores of high and low ability pupils taught mathematics using activity based learning approach.

Ho3: There is no significant difference between the mathematics creative ability mean scores of male and female pupils taught mathematics using activity based learning approach.

Table 1. Summary of pupils' mathematics creative mean scores

\begin{tabular}{|c|c|c|c|c|c|c|}
\hline Group & $\mathrm{N}$ & Test & mean & SD & Diff in mean & Ach diff \\
\hline \multirow[t]{2}{*}{ Expt } & 78 & Pretest & 31.56 & 8.22 & 18.18 & 16.74 \\
\hline & & Posttest & 49.74 & 8.64 & & \\
\hline \multirow[t]{2}{*}{ Cont } & 102 & Pretest & 32.42 & 8.87 & 1.43 & \\
\hline & & Posttest & 33.85 & 11.50 & & \\
\hline
\end{tabular}

Table 2. Summary of mathematics creative mean scores of high and low ability pupils

\begin{tabular}{|c|c|c|c|c|c|c|}
\hline Achievers & $\mathrm{N}$ & Test & mean & SD & Diff in mean & Ach diff \\
\hline \multirow[t]{2}{*}{ High } & 25 & Pretest & 32.69 & 8.68 & 13.42 & 8.52 \\
\hline & & Posttest & 46.11 & 12.26 & & \\
\hline \multirow[t]{2}{*}{ Low } & 53 & Pretest & 31.28 & 8.45 & 4.86 & \\
\hline & & Posttest & 36.14 & 11.84 & & \\
\hline
\end{tabular}

Table 3. Summary of mathematics creativity mean scores based on gender

\begin{tabular}{|c|c|c|c|c|c|c|}
\hline Gender & $\mathrm{N}$ & Test & mean & SD & Diff in mean & Ach diff \\
\hline \multirow[t]{2}{*}{ Male } & 35 & Pretest & 31.75 & 8.85 & 19.51 & 3.04 \\
\hline & & Posttest & 51.26 & 8.44 & & \\
\hline \multirow[t]{2}{*}{ Female } & 43 & Pretest & 32.28 & 8.40 & 16.43 & \\
\hline & & Posttest & 48.51 & 8.72 & & \\
\hline
\end{tabular}

Table 4. Summary of ANCOVA analysis

\begin{tabular}{|c|c|c|c|c|c|}
\hline Source & Type III sum of squares & $\mathrm{df}$ & Mean Square & $\mathrm{F}$ & Sig \\
\hline Corrected Model & 12047.375 & 6 & 2007.896 & 19.055 & .000 \\
\hline Intercept & 16743.263 & 1 & 16743.263 & 158.897 & .000 \\
\hline Covariate & 199.814 & 1 & 199.814 & 1.896 & .170 \\
\hline Gender & 18.281 & 1 & 18.281 & 173 & .678 \\
\hline Method & 11775.590 & 1 & 11775.590 & 111.753 & .000 \\
\hline Ability & 100.555 & 1 & 100.555 & .954 & .330 \\
\hline gender*Method & 191.415 & 1 & 191.415 & 1.817 & .179 \\
\hline Method*Achievers & 6.306 & 1 & 6.306 & 0.60 & .807 \\
\hline Error & 18229.352 & 173 & 105.372 & & \\
\hline Total & 329015.000 & 180 & & & \\
\hline Corrected Total & 30276.728 & 179 & & & \\
\hline
\end{tabular}

\section{Discussions}

The results of the study revealed that activity based learning approach is very effective in enhancing primary school pupils creative ability in mathematics. This was evident in the mean scores of primary school pupils as those taught mathematics using activity based learning approach had better mathematics creative ability mean scores than those taught through traditional approach. Further statistical analysis indicated a significant difference in mean scores of both groups which was in favour of those taught mathematics using activity based learning approach. This may have resulted because activities in mathematics classes provide the pupils opportunities to work with tangible materials and increase their motivation to learn. It may also be that, the presentation of the content using activity based learning approach made it easier for pupils to learn the subject, granted access to more solutions to presented problem situations and related it to daily life. The result is in agreement with Sajna and Bincy (2015) who stated that while teaching Mathematics, one should use the teaching methods, strategies, and pedagogic resources that are more fruitful in gaining adequate responses from the students and Sharma (n.d) which revealed that strategy for fostering mathematics creativity was found to enhance mathematical creativity of students.

The study revealed that activity based learning approach enhanced mathematics creativity of primary school pupils irrespective of ability levels as high and low ability pupils in the experiment group had improved mean scores. Further statistical analysis indicated no statistical significant difference between the mean scores of the two ability levels. The result is suspected to be due to the nature of the approach, as it didn't permit any form of discrimination and competition among the pupils, every 
member of the group had opportunity to understand the concept thought, made useful contributions, manipulated the materials individually and collectively while the high achievers interacted with low achievers guiding them when needed. The approach provided pupils with ability to interpret, reason, analyze and synthesize, the bundles of information presented to them in the classroom. This result is in disagreement with that of Padav (2015) which revealed a significant difference in achievement scores of students with different level of intelligence (high, average, low) taught mathematics using activity based teaching.

The results of the study also revealed that activity based learning approach enhanced creative ability of primary school pupils irrespective of their gender as indicated by their achievements. There existed no statistical significant difference between mathematics achievement of male and female pupils taught mathematics using activity based learning approach. This was suspected to have occurred because the approach allowed male and female pupils to interact with each other in seeking solution to problem situations and allowed them tryout unpopular methods of solving such problems through manipulation of pedagogic resources. This result is in agreement with the findings of Nwoke, Nwoga and Emenyeonu (2018) which revealed that enhancement of students' mathematical creativity through technology usage is not dependent on gender and Sharma(n.d) which revealed no significant difference between male and female students in regards to their mathematical creativity scores due to strategy for fostering mathematics creativity.

\section{CONCLUSION}

The results of the study has revealed that activity-based learning approach is very effective in enhancing primary school pupils creativity in mathematics irrespective of gender and ability levels.

\section{RECOMMENDATION}

Based on the results of the study, the following recommendations were made: 1) Primary school teachers should make use of pupil-centered approaches such as activity-based learning in teaching to enable the pupils to improve in mathematics creativity, 2) Pedagogic resources should be applied in teaching mathematics at the primary school level to provide hands-on learning which will enhance pupils' creative ability and achievement, and 3) Teachers training programs should be geared towards developing teachers who will apply the necessary pedagogical approaches that build pupils' creative ability and enhance their achievement in mathematics.

\section{Acknowledgement}

The authors would like to thank all parties who have assisted in the research and writing of this manuscript so that it deserves to be widely published to the academic community.

\section{REFERENCES}

Ayele, M.A. (2016). Mathematics teachers' perceptions on enhancing students' creativity in mathematics. IEJMEMathematics Education 11(10),3521-3536.

Azuka,B.F.(2013). Activity -based learning strategies in the mathematics classrooms. Journal of Education and Practice 4(13), 8-14.

Celik, H.C. (2018). The effects of activity-based learning on sixth grade students' achievement and attitudes towards mathematics activities. EURASIA Journal of Mathematics, Science and Technology Education,14(5), 1963-1977.

Malhotra, S., Singh, S. K., Pandey, G.P., Nayyar, S., Sharma, A., \& Singh, T. (2015). Study package for CTET (Paper 1). McGraw Hill Education (India) Private Limited. Green Park Extension, New Delhi.

Mehdi, N., Narges Y. \& Shahrnaz, B. (2012). Mathematical creativity: some definitions and characteristics. ProcediaSocial and Behavioral Sciences 31, 285- 291.

Mkpae, S. G. \& Obowu-Adutchay, V. (2017). Teaching for creative thinking. International Journal of Education and Evaluation. $3(2), 28-33$.

NCF (2005). National Curriculum Framework. New Delhi: National Council of Educational Research and Training.

NCTM. (2000). Principles and standards for school mathematics. Reston,VA, Author.

Okwudishu, A.U (2011). Trainer guide to the use of the manual of best practices and methods of facilitating in basic literacy programme. A Lead Paper Presented during a Workshop on Developing Manual of Best Practices at Enugu, Nigeria.

Sajna, J \& Bincy, T. (2015). Development of mathematical creativity in India through ages: A historical sketch of Post Independence period. International Journal of Applied Research 1(12): 891-894.

Sharma, Y. (n.d). Facilitation of mathematical creativity through strategy rich in problem posing and problem solving.

Sriraman, B. (2004). The-characteristics of mathematical creativity. The International Journal on Mathematics Education [ZDM], 41, 13-27.

Vale, I \& Barbosa, A. (2015). Mathematics creativity in elementary teacher training. Journal of the European Teacher Education Network 10, 101-109.

Vale, I., Pimentel, T., Cabrita, I., Barbosa, A. \& Fonseca, L. (2012). Pattern problem solving tasks as a mean to foster creativity in mathematics. Tso, T. Y. (Ed), Opportunities to learn in mathematics education, Proceedings of the 36th Conference of the International Group for the Psychology of Mathematics Education, 4, 171-178. Taipei, Taiwan: PME. 
Yadav, P. (2015). Effect of activity-based teaching on achievement of students in mathematics at primary level. International Journal of Advanced Research in Education and Technology, 2(4), 157-159. 